\title{
Predicting the combined occurrence of poor clinical and radiographic outcomes following cervical deformity corrective surgery
}

\author{
Samantha R. Horn, BA, ${ }^{1}$ Peter G. Passias, MD,, Cheongeun Oh, PhD, ${ }^{1}$ Virginie Lafage, PhD, ${ }^{2}$ \\ Renaud Lafage, MS, ${ }^{2}$ Justin S. Smith, MD, PhD, ${ }^{3}$ Breton Line, BS, ${ }^{4}$ Neel Anand, MD, ${ }^{5}$ \\ Frank A. Segreto, BS, ${ }^{1}$ Cole A. Bortz, BA, ${ }^{1}$ Justin K. Scheer, MD, ${ }^{6}$ Robert K. Eastlack, MD, \\ Vedat Deviren, MD, ${ }^{8}$ Praveen V. Mummaneni, MD, ${ }^{8}$ Alan H. Daniels, MD, ${ }^{9}$ Paul Park, MD, ${ }^{10}$ \\ Pierce D. Nunley, MD,11 Han Jo Kim, MD, ${ }^{11}$ Eric O. Klineberg, MD, ${ }^{12}$ Douglas C. Burton, MD, ${ }^{13}$ \\ Robert A. Hart, MD, ${ }^{14}$ Frank J. Schwab, MD, ${ }^{2}$ Shay Bess, MD, ${ }^{4}$ Christopher I. Shaffrey, MD, ${ }^{3}$ \\ Christopher P. Ames, MD, ${ }^{15}$ and the International Spine Study Group
}

'Department of Orthopaedics, NYU Langone Medical Center-Orthopaedic Hospital, New York, New York; ${ }^{2}$ Department of Orthopaedic Surgery, Hospital for Special Surgery, New York, New York; ${ }^{3}$ Department of Neurosurgery, University of Virginia Health System, Charlottesville, Virginia; ${ }^{4}$ Denver International Spine Center, Presbyterian/St. Luke's Medical Center and Rocky Mountain Hospital for Children, Denver, Colorado; ${ }^{5}$ Department of Orthopaedic Surgery, Cedars-Sinai Medical Center, Los Angeles, California; ${ }^{\circ}$ Department of Neurosurgery, University of Illinois at Chicago, Illinois; ${ }^{7}$ Department of Orthopaedic Surgery, Scripps Health, La Jolla, California; ${ }^{8}$ Department of Orthopaedic Surgery, University of California, San Francisco, California; ${ }^{9}$ Department of Orthopaedic Surgery, Brown University Medical Center, Providence, Rhode Island; ${ }^{10}$ Department of Neurosurgery, University of Michigan, Ann Arbor, Michigan; ${ }^{11}$ Department of Orthopedic Surgery, Spine Institute of Louisiana, Shreveport, Louisiana; ${ }^{12}$ Department of Orthopedic Surgery, University of California Davis, Sacramento, California; ${ }^{13}$ Department of Orthopaedic Surgery, University of Kansas Medical Center, Kansas City, Kansas; ${ }^{14}$ Department of Orthopaedic Surgery, Swedish Neuroscience Institute, Seattle, Washington; and ${ }^{15}$ Department of Neurological Surgery, University of California, San Francisco, California

OBJECTIVE Cervical deformity (CD) correction is clinically challenging. There is a high risk of developing complications with these highly complex procedures. The aim of this study was to use baseline demographic, clinical, and surgical factors to predict a poor outcome following CD surgery.

METHODS The authors performed a retrospective review of a multicenter prospective CD database. CD was defined as at least one of the following: cervical kyphosis (C2-7 Cobb angle $>10^{\circ}$ ), cervical scoliosis (coronal Cobb angle $>10^{\circ}$ ), C2-7 sagittal vertical axis (cSVA) $>4 \mathrm{~cm}$, or chin-brow vertical angle $(\mathrm{CBVA})>25^{\circ}$. Patients were categorized based on having an overall poor outcome or not. Health-related quality of life measures consisted of Neck Disability Index (NDI), EQ-5D, and modified Japanese Orthopaedic Association (mJOA) scale scores. A poor outcome was defined as having all 3 of the following categories met: 1) radiographic poor outcome: deterioration or severe radiographic malalignment 1 year postoperatively for cSVA or T1 slope-cervical lordosis mismatch (TS-CL); 2) clinical poor outcome: failing to meet the minimum clinically important difference (MCID) for NDI or having a severe mJOA Ames modifier; and 3) complications/reoperation poor outcome: major complication, death, or reoperation for a complication other than infection. Univariate logistic regression followed by multivariate regression models was performed, and internal validation was performed by calculating the area under the curve (AUC).

RESULTS In total, 89 patients with CD were included (mean age 61.9 years, female sex $65.2 \%, \mathrm{BMI} 29.2 \mathrm{~kg} / \mathrm{m}^{2}$ ). By 1 year postoperatively, $18(20.2 \%)$ patients were characterized as having an overall poor outcome. For radiographic poor outcomes, patients' conditions either deteriorated or remained severe for TS-CL (73\% of patients), cSVA ( $8 \%$ ), horizontal gaze $(34 \%)$, and global SVA (28\%). For clinical poor outcomes, $80 \%$ and $60 \%$ of patients did not reach MCID for EQ-5D and NDI, respectively, and $24 \%$ of patients had severe symptoms (mJOA score $0-11$ ). For the complications/reoperation

ABBREVIATIONS AUC = area under the curve; CBVA = chin-brow vertical angle; $C D=$ cervical deformity; $C L=C 2-7$ lordosis; $c S V A=C 2-7$ SVA; MCID = minimum clinically important difference; $\mathrm{mJOA}=$ modified Japanese Orthopaedic Association; NDI = Neck Disability Index; PI-LL = mismatch between pelvic incidence and lumbar lordosis; $\mathrm{PT}=$ pelvic tilt; $\mathrm{SVA}=$ sagittal vertical axis; $\mathrm{TS}-\mathrm{CL}=$ mismatch between $\mathrm{T} 1$ slope and $\mathrm{CL}$.

SUBMITTED May 25, 2018. ACCEPTED July 9, 2019.

INCLUDE WHEN CITING Published online November 1, 2019; DOI: 10.3171/2019.7.SPINE18651. 
poor outcome, 28 patients experienced a major complication, 11 underwent a reoperation, and 1 had a complicationrelated death. Of patients with a poor clinical outcome, $75 \%$ had a poor radiographic outcome; $35 \%$ of poor radiographic and $37 \%$ of poor clinical outcome patients had a major complication. A poor outcome was predicted by the following combination of factors: osteoporosis, baseline neurological status, use of a transition rod, number of posterior decompressions, baseline pelvic tilt, T2-12 kyphosis, TS-CL, C2-T3 SVA, C2-T1 pelvic angle (C2 slope), global SVA, and number of levels in maximum thoracic kyphosis. The final model predicting a poor outcome (AUC $86 \%$ ) included the following: osteoporosis (OR 5.9, 95\% Cl 0.9-39), worse baseline neurological status (OR 11.4, 95\% Cl 1.8-70.8), baseline pelvic tilt $>20^{\circ}(\mathrm{OR} 0.92,95 \% \mathrm{Cl} 0.85-0.98)$, > 9 levels in maximum thoracic kyphosis (OR 2.01, 95\% $\left.\mathrm{Cl} 1.1-4.1\right)$, preoperative C2-T3 SVA > $5.4 \mathrm{~cm}$ (OR 1.01, 95\% Cl 0.9-1.1), and global SVA > $4 \mathrm{~cm}$ (OR 3.2, 95\% Cl 0.09-10.3).

CONCLUSIONS Of all CD patients in this study, $20.2 \%$ had a poor overall outcome, defined by deterioration in radiographic and clinical outcomes, and a major complication. Additionally, $75 \%$ of patients with a poor clinical outcome also had a poor radiographic outcome. A poor overall outcome was most strongly predicted by severe baseline neurological deficit, global SVA $>4 \mathrm{~cm}$, and including more of the thoracic maximal kyphosis in the construct.

https://thejns.org/doi/abs/10.3171/2019.7.SPINE18651

KEYWORDS cervical deformity; poor outcome; complications; predictive analytics; sagittal malalignment

$\mathrm{C}$ ERVICAL deformity (CD) includes a complex range of disorders with varying etiologies, from trauma, spondylosis, congenital conditions, and others. ${ }^{22}$ Although uncommon, severe CD can lead to debilitating consequences and can result in severe disability and pain related to neurological impairment. ${ }^{18,20}$ As opposed to thoracolumbar deformities, the CD literature lacks a strong agreement on the characterization and classification of the condition. $^{2}$

As CD surgery has progressed, it has become increasingly more common for surgeons to operate on more challenging cases in higher-risk patients. There is a large amount in variability in both treatment techniques and surgical planning for $\mathrm{CD}$ that in part might contribute to the wide range of outcomes and complications experienced by patients..$^{21}$ Additionally, CD patients are a distinct cohort from patients with thoracolumbar deformities, as they are more frail, have more heterogeneous pathologies, and oftentimes undergo more high-risk surgeries with unique complications, including C5 palsy and dysphagia. ${ }^{9,24}$ Increased age and presence of other comorbidities also put patients at risk of having poor outcomes following surgery; however, these high-risk patients are increasingly becoming more of the typical CD patient who undergoes surgical treatment. Additionally, baseline radiographic and clinical assessments influence postoperative outcomes and need to be taken into account when planning surgical procedures..$^{19}$ One recent study showed that worse baseline malalignment was associated with inferior postoperative outcomes following CD corrective surgery. ${ }^{16}$ Other investigations have examined the importance of including the primary driver of the deformity in the construct, otherwise leading to residual malalignment and inferior health-related quality of life scores, which stresses the importance of preoperative alignment on postoperative outcomes. ${ }^{12}$

The use of predictive analytics in the field of spine surgery provides a means to determine patient-specific factors that predict a particular outcome of interest. Given that surgeons and their patients are invested in obtaining the most positive outcomes possible, determining specific factors that affect outcomes is of utmost importance.

Identifying patient-specific factors that predict a poor outcome after $\mathrm{CD}$ surgery may help to improve patient outcomes. Therefore, the aim of this study was to use baseline demographic, clinical, and surgical factors to predict a poor overall outcome following $\mathrm{CD}$ corrective surgery.

\section{Methods \\ Patient Population}

This study is a retrospective review of a prospectively collected database of surgical CD patients enrolled from 13 sites within the United States from 2013 to 2017. Institutional review board approval was obtained at each participating site prior to study initiation, and informed consent was given by each included patient. Inclusion criteria for the database were patient age $\geq 18$ years and radiographic evidence of $\mathrm{CD}$ at baseline assessment, defined as the presence of at least one of the following: cervical kyphosis $\left(\mathrm{C} 2-7 \mathrm{Cobb}\right.$ angle $\left.>10^{\circ}\right)$, cervical scoliosis $(\mathrm{C} 2-$ 7 coronal Cobb angle $>10^{\circ}$ ), C2-7 sagittal vertical axis (cSVA) $>4 \mathrm{~cm}$, or chin-brow vertical angle $(\mathrm{CBVA})>25^{\circ}$. $\mathrm{CD}$ patients meeting radiographic inclusion with available baseline and 1-year follow-up data were included in this study. Patients with active tumors or infections were excluded from the study.

\section{Patient Inclusion and Exclusion}

A total of $154 \mathrm{CD}$ patients were included in the database used in this study. Of these patients, 65 were excluded because they did not have complete baseline and 1-year postoperative radiographic and clinical data. This limited our cohort to 89 patients included for analysis.

\section{Data Collection}

Demographic and clinical data collected included patient age, sex, BMI, prior cervical surgery, and Charlson Comorbidity Index. Surgical data collected included operative time, estimated blood loss, surgical approach, offlabel use of bone morphogenetic protein-2, osteotomy use and number of osteotomies, levels fused, and instrumentation used.

Patients were evaluated using full-length free-standing lateral spine radiographs (36-inch-long cassette) at baseline and the 1-year postoperative follow-up visit. Radiographs were analyzed using dedicated and validated soft- 

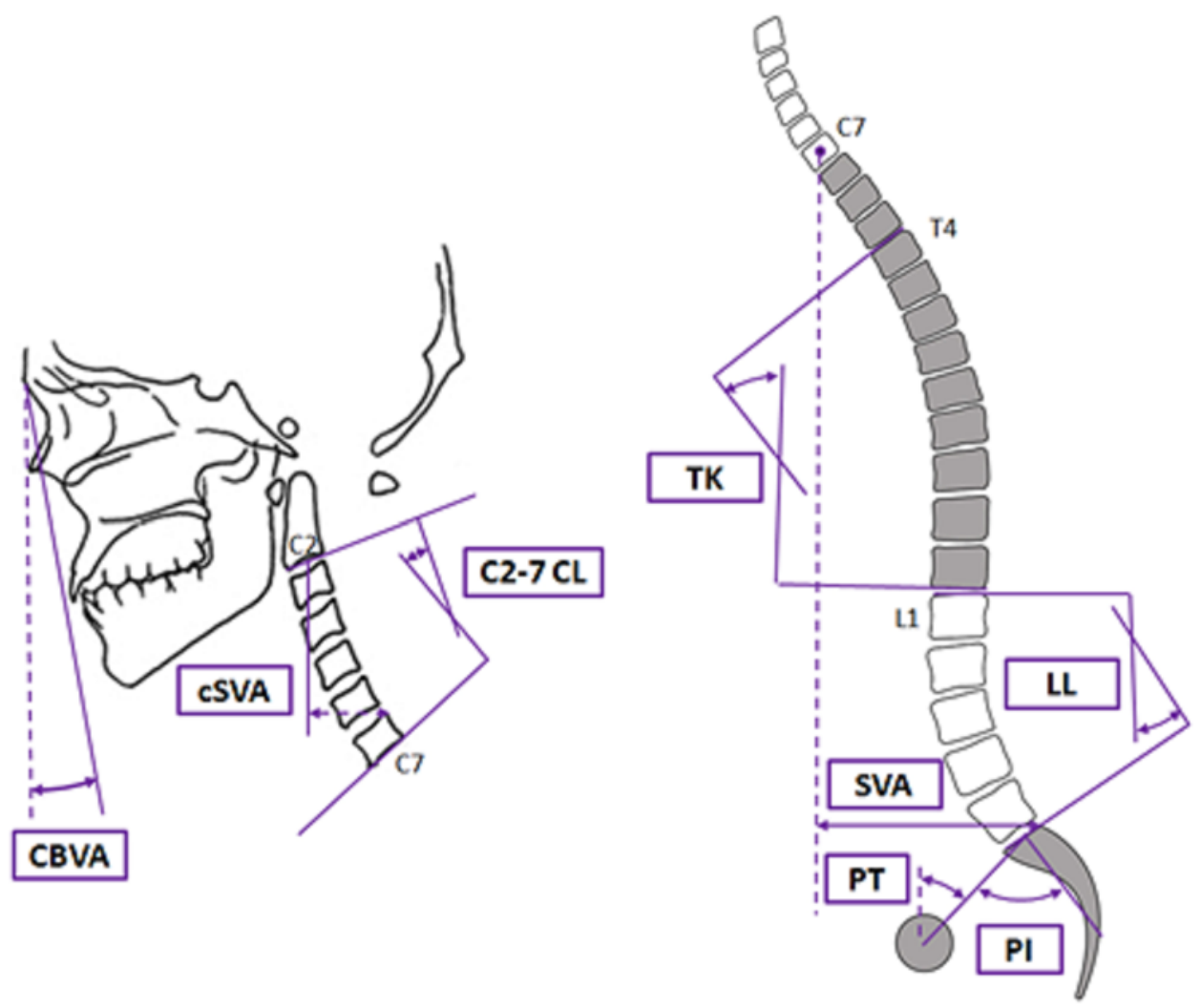

FIG. 1. Schematic of the measured sagittal alignment parameters for the cervical (left) and global spinopelvic (right) spinal regions. CBVA = chin-brow vertical angle; cSVA = cervical sagittal vertical axis; $\mathrm{C2}-7 \mathrm{CL}=$ cervical lordosis; $\mathrm{TK}=$ thoracic kyphosis; $\mathrm{LL}=$ lumbar lordosis; SVA = sagittal vertical axis; $\mathrm{PT}$ = pelvic tilt; $\mathrm{PI}=$ pelvic incidence. Figure is available in color online only.

ware (SpineView, ENSAM, Laboratory of Biomechanics) at a single center with standard techniques. ${ }^{5,10,17}$ Measured cervical spine parameters included cSVA (offset from the $\mathrm{C} 2$ plumb line and the posterosuperior corner of $\mathrm{C} 7$ ), C2-7 lordosis (CL; Cobb angle between C2 inferior endplate and C7 inferior endplate), T1 slope minus CL (TSCL; mismatch between T1 slope and CL), C2-T3 angle and SVA, and CBVA (angle subtended between the vertical line and the line from the brow to the chin). Measured spinopelvic parameters (Fig. 1) included sagittal vertical axis (SVA; C7 plumb line relative to the posterosuperior corner of S1), pelvic incidence minus lumbar lordosis (PILL; mismatch between pelvic incidence and lumbar lordosis), and pelvic tilt (PT; angle between the vertical and the line through the sacral midpoint to the center of the 2 femoral heads).

\section{Defining a Poor Outcome}

A poor outcome was defined as having all 3 of the following categories met: 1) radiographic poor outcome: deterioration (baseline to 1-year postoperative increase) or severe radiographic malalignment 1 year postoperatively for cSVA $(>8 \mathrm{~cm})$ or TS-CL $\left(>20^{\circ}\right) ; 2$ ) clinical poor outcome: failing to meet the minimum clinically important difference (MCID) for the Neck Disability Index (NDI) (defined as a change by 15 points or more) or having severe symptoms (modified Japanese Orthopaedic Association [mJOA] Ames modifier score 0-11); and 3) complications/ reoperation poor outcome: major complication, death, or reoperation for a complication other than infection. ${ }^{1,2}$ Major complications were defined as previously published: complications involving invasive intervention, prolonged or permanent morbidity, or a complication that resulted in death. ${ }^{24}$

\section{Statistical Analysis}

Demographic and clinical variables were assessed using chi-square and t-tests for categorical and continuous variables, respectively. Univariate logistic regression followed by multivariate regression models was performed, and internal validation was performed by calculating the area under the curve (AUC). Two-sided $p$ values $<0.05$ were considered statistically significant. All statistical analyses were performed using IBM SPSS (version 23, IBM Corp.).

\section{Results}

\section{Study Population}

Eighty-nine patients with $\mathrm{CD}$ were included (mean age 61.9 years, female sex $65.2 \%$, BMI $29.2 \mathrm{~kg} / \mathrm{m}^{2}$; Table 1). The most common diagnoses for these $\mathrm{CD}$ patients were degenerative kyphosis (50.9\%), cervical stenosis (12\%), and iatrogenic kyphosis $(10.9 \%)$. Patient comorbidities included depression in $30.3 \%$, osteoporosis in $14.6 \%$, and diabetes in $7.9 \%$. Of all patients, $38.6 \%$ had a prior cervi- 
TABLE 1. Overall cohort demographics and surgical details for the $C D$ population in this study

\begin{tabular}{lc}
\hline & Mean or Frequency \\
\hline Patient demographics & \\
\hline Mean age, yrs & 61.9 \\
\hline Female sex & $65.2 \%$ \\
\hline Mean BMl, kg/m ${ }^{2}$ & 29.2 \\
\hline History of cervical spine surgery & $38.6 \%$ \\
\hline Osteoporosis & $14.6 \%$ \\
\hline Diabetes & $7.9 \%$ \\
\hline Depression & $30.3 \%$ \\
\hline Surgical details & \\
\hline Mean no. of levels fused & $7.61 \pm 3.59$ \\
\hline Mean EBL, mL & $862.2 \pm 887.1$ \\
\hline Mean operative time, mins & $376.6 \pm 317.5$ \\
\hline Surgical approach & $16.9 \%$ \\
\hline Anterior only & $49.4 \%$ \\
\hline Posterior only & $33.7 \%$ \\
\hline Combined & $21.3 \%$ \\
\hline 3-column osteotomy &
\end{tabular}

$\mathrm{EBL}=$ estimated blood loss.

cal spine surgery. CD correction involved a mean $( \pm$ SD) of $7.61 \pm 3.59$ levels fused, with an average operative time of $376.6 \pm 317.5$ minutes and estimated blood loss of 862.2 $\pm 887.1 \mathrm{~mL}$. The surgical approach was anterior only in $16.9 \%$, posterior only in $49.4 \%$, and combined approach in $33.7 \%$, with $21.3 \%$ of patients undergoing a 3 -column osteotomy. In the overall cohort, 18 (20.2\%) patients had a poor overall outcome (clinical, radiographic, and complications/reoperation) by the 1-year follow-up. The rate of osteoporosis was significantly higher for patients who had a poor overall outcome than for those who did not $(33.3 \%$ vs $9.9 \%, p=0.021)$. None of the other demographic, clinical, and surgical details were significantly different when compared between poor outcome patients and those without a poor outcome (all $\mathrm{p}>0.05$ ).

\section{Pre- and Postoperative Radiographic Alignment}

This cohort of CD patients had an average preoperative C2-7 lordosis of $-7.09^{\circ} \pm 21.02^{\circ}$, TS-CL of $37.32^{\circ} \pm$ $19.27^{\circ}$, and cSVA of $46.05 \pm 24.91 \mathrm{~mm}$ (Table 2). Preoperative and 1-year postoperative changes in cervical, cervicothoracic, and global spinal alignment parameters are shown in Table 2. None of the cervical, cervicothoracic, and global alignment parameters differed at baseline between patients with and without an overall poor outcome, with the exception of pelvic tilt (Table 3). At 1 year postoperatively, patients with an overall poor outcome had worse cSVA, C2-T3 SVA, TS-CL, and C2 slope than patients without an overall poor outcome (all $\mathrm{p}<0.05$, Table 3 ).

\section{Health-Related Quality of Life Scores and Baseline Neuro- logical Status}

At baseline, this CD cohort had an average NDI score of 48.5, EQ-5D of 0.73 , and mJOA score of 13.5 (Table
TABLE 2. Radiographic assessment of the CD cohort at baseline and 1 year postoperatively

\begin{tabular}{|c|c|c|c|}
\hline Radiographic Parameter & Preop & Postop & $\mathrm{p}$ Value \\
\hline SVA, mm & $2.67 \pm 69.8$ & $25.4 \pm 70.03$ & $<0.001$ \\
\hline $\mathrm{PT},{ }^{\circ}$ & $19.5 \pm 11.9$ & $18.9 \pm 11.3$ & 0.314 \\
\hline PI-LL, ${ }^{\circ}$ & $1.25 \pm 18.5$ & $2.03 \pm 18.44$ & 0.484 \\
\hline C2-7 CL, ${ }^{\circ}$ & $-7.09 \pm 21.02$ & $6.96 \pm 16.02$ & $<0.001$ \\
\hline cSVA, mm & $46.05 \pm 24.91$ & $40.97 \pm 17.89$ & 0.008 \\
\hline C2-T3 angle, ${ }^{\circ}$ & $-17.09 \pm 11.9$ & $-1.57 \pm 17.75$ & $<0.001$ \\
\hline C2-T3 SVA, mm & $78.05 \pm 40.22$ & $76.61 \pm 28.10$ & 0.433 \\
\hline T4-12 thoracic kyphosis, ${ }^{\circ}$ & $39.1 \pm 15.9$ & $42.87 \pm 15.28$ & $<0.001$ \\
\hline TS-CL, ${ }^{\circ}$ & $37.32 \pm 19.27$ & $28.10 \pm 13.29$ & $<0.001$ \\
\hline C2 slope, ${ }^{\circ}$ & $37.81 \pm 20.49$ & $27.07 \pm 14.25$ & $<0.001$ \\
\hline
\end{tabular}

Boldface type indicates statistical significance.

4). Twenty-six percent of CD patients had no neurological deficit at baseline. At baseline, $54 \%$ of patients presented with hand numbness, $43.8 \%$ with weakness, $38.2 \%$ with gait impairment, and $36 \%$ with hand clumsiness.

\section{Poor Outcome Clusters}

In looking at the radiographic poor outcomes, $73 \%$ of patients worsened in TS-CL or remained severely malaligned postoperatively and $8 \%$ of patients worsened or had severe cSVA (Table 5). Eighty percent of CD patients failed to meet the MCID for EQ-5D, $60 \%$ failed to meet the MCID for NDI, and 24\% of patients had a severe mJOA score (0-11) postoperatively. In looking at complications, $32 \%$ of the cohort experienced a major complication and $12 \%$ underwent a reoperation. The mortality rate of this cohort was $1 \%$.

Seventy-five percent of patients who had a poor clinical outcome also had a poor radiographic outcome, 35\% of patients with a poor radiographic outcome had a major complication, and $37 \%$ of patients with a poor clinical outcome experienced a major complication.

\section{Predictive Model for an Overall Poor Outcome}

Factors associated with an overall poor outcome (radiographic, clinical, and complications/reoperation) included the following independent baseline predictors: osteoporosis, baseline neurological status, use of a transition rod, posterior decompression, pelvic tilt, T2-12 thoracic kyphosis, T1 slope, C2-T3 SVA, C2-T1 pelvic angle (C2 slope), global SVA, and higher number of levels in maximal thoracic kyphosis.

An overall poor outcome was predicted with high accuracy (AUC 86\%) using the following combination of factors in the final model: presence of baseline neurological deficit, osteoporosis, baseline global SVA $>4 \mathrm{~cm},>9$ levels in maximal thoracic kyphosis, baseline C2-T3 SVA $>5.4$ $\mathrm{cm}$, and baseline pelvic tilt $>20^{\circ}$ (Table 6 ).

\section{Case Examples}

Figure 2 displays a case example of a 69 -year-old male patient with $\mathrm{CD}$ with a prior anterior fusion who was now undergoing a posterior fusion from $\mathrm{C} 2$ to $\mathrm{T} 4$. His risk fac- 
TABLE 3. Preoperative and postoperative radiographic assessment of the CD cohort compared between patients with and without an overall poor outcome

\begin{tabular}{|c|c|c|c|}
\hline & Not Poor Outcome $(n=71)$ & Poor Outcome $(n=18)$ & $\mathrm{p}$ Value \\
\hline \multicolumn{4}{|l|}{ Baseline radiographic parameter } \\
\hline SVA, mm & $-0.64 \pm 61.45$ & $15.41 \pm 96.58$ & 0.388 \\
\hline $\mathrm{PT},{ }^{\circ}$ & $20.77 \pm 10.4$ & $14.51 \pm 16.33$ & 0.047 \\
\hline Pl-LL, ${ }^{\circ}$ & $2.7 \pm 16.04$ & $-4.47 \pm 25.84$ & 0.143 \\
\hline $\mathrm{C} 2-7 \mathrm{CL},{ }^{\circ}$ & $-8.16 \pm 18.63$ & $-3.12 \pm 28.56$ & 0.384 \\
\hline cSVA, mm & $43.8 \pm 25.79$ & $54.39 \pm 19.8$ & 0.120 \\
\hline C2-T3 angle, ${ }^{\circ}$ & $-16.89 \pm 18.71$ & $-17.86 \pm 28.13$ & 0.866 \\
\hline C2-T3 SVA, mm & $73.67 \pm 40.7$ & $94.31 \pm 34.82$ & 0.060 \\
\hline T4-12 thoracic kyphosis, ${ }^{\circ}$ & $-38.06 \pm 15.63$ & $-43.18 \pm 16.94$ & 0.225 \\
\hline $\mathrm{TS}^{\mathrm{T}} \mathrm{CL},{ }^{\circ}$ & $36.42 \pm 18.29$ & $40.67 \pm 22.84$ & 0.424 \\
\hline C2 slope, ${ }^{\circ}$ & $36.61 \pm 19.58$ & $42.25 \pm 23.7$ & 0.317 \\
\hline \multicolumn{4}{|l|}{ 1-yr radiographic parameter } \\
\hline SVA, mm & $23.36 \pm 57.83$ & $29.56 \pm 106.53$ & 0.744 \\
\hline $\mathrm{PT},{ }^{\circ}$ & $20.04 \pm 11.11$ & $14.19 \pm 11.29$ & 0.050 \\
\hline $\mathrm{PI}-\mathrm{LL}, \stackrel{\circ}{\circ}$ & $3.65 \pm 17.49$ & $-4.38 \pm 21.16$ & 0.099 \\
\hline $\mathrm{C} 2-7 \mathrm{CL},{ }^{\circ}$ & $7.54 \pm 15.16$ & $7.52 \pm 18.08$ & 0.996 \\
\hline cSVA, mm & $39.35 \pm 17.41$ & $49.15 \pm 16.65$ & 0.040 \\
\hline C2-T3 angle, ${ }^{\circ}$ & $0.13 \pm 15.86$ & $-5.04 \pm 23.25$ & 0.281 \\
\hline C2-T3 SVA, mm & $74.2 \pm 27.3$ & $89.01 \pm 26.57$ & 0.048 \\
\hline T4-12 kyphosis, $^{\circ}$ & $-41.71 \pm 15.5$ & $-47.72 \pm 13.68$ & 0.147 \\
\hline TS-CL, ${ }^{\circ}$ & $25.91 \pm 12.15$ & $35.29 \pm 14.29$ & 0.007 \\
\hline C2 slope, ${ }^{\circ}$ & $24.84 \pm 12.68$ & $34.31 \pm 16.24$ & 0.011 \\
\hline
\end{tabular}

Boldface type indicates statistical significance.

tors for a poor outcome included the following combination of factors: baseline neurological deficit (weakness, gait impairment, hand muscle atrophy), baseline C2-T3 SVA of $84.7 \mathrm{~mm}$, baseline pelvic tilt of $18.1^{\circ}$, and 12 levels in maximal thoracic kyphosis. Postoperatively, this patient had worsening TS-CL (preoperative: $54.4^{\circ}$; postoperative:

TABLE 4. Baseline health-related quality of life (HRQOL) scores and neurological status of the CD cohort

\begin{tabular}{cc}
\hline Metric & Mean or Frequency \\
\hline Mean HRQOL score & \\
\hline Baseline NDI & $48.5 \pm 16.7$ \\
\hline Baseline EQ-5D & $0.73 \pm 0.06$ \\
\hline Baseline mJOA & $13.5 \pm 2.7$ \\
\hline Neurological status & \\
\hline Bladder issues & $11.2 \%$ \\
\hline Bowel issues & $4.5 \%$ \\
\hline Gait impairment & $38.2 \%$ \\
\hline Hand clumsiness & $36 \%$ \\
\hline Hand numbness & $54 \%$ \\
\hline Lhermitte's sign & $6.7 \%$ \\
\hline Bilateral paresthesia & $23.6 \%$ \\
\hline Weakness & $43.8 \%$ \\
\hline No deficit & $26 \%$ \\
\hline
\end{tabular}

$72.4^{\circ}$ ) and cSVA (preoperative: $56.9 \mathrm{~mm}$, postoperative: $61.9 \mathrm{~mm}$ ) malalignment, and failed to reach MCID for the mJOA score (preoperative: 10; postoperative: 11), although his NDI score improved (preoperative: 84 ; postoperative: 68). This patient developed distal junctional kyphosis by 6 months postoperatively and required a reoperation.

A case example of a 63-year-old female CD patient with a prior thoracolumbar fusion who was now undergoing a posterior fusion from C5-T2 is shown in Fig. 3.

TABLE 5. Breakdown of each category for the poor outcomes for CD patients

\begin{tabular}{cc}
\hline \multicolumn{1}{c}{ Poor Outcome } & Frequency \\
\hline Radiographic & \\
\hline TS-CL & $73 \%$ \\
\hline cSVA & $8 \%$ \\
\hline Clinical & \\
\hline Failed to meet EQ-5D MCID & $80 \%$ \\
\hline Failed to meet NDI MCID & $60 \%$ \\
\hline mJOA score <12 & $24 \%$ \\
\hline Complications/reoperation & \\
\hline Major complication & $32 \%$ \\
\hline Reop & $12 \%$ \\
\hline Death & $1 \%$ \\
\hline
\end{tabular}


TABLE 6. Final predictive model for predicting an overall poor outcome in $\mathrm{Cl}$ patients*

\begin{tabular}{lcc}
\hline \multicolumn{1}{c}{ Model Predicting a Poor Outcome } & OR & $\mathrm{Cl}$ \\
\hline Baseline neurological deficit† & 11.4 & $1.8-70.8$ \\
\hline Osteoporosis & 5.9 & $0.9-39$ \\
\hline Baseline global SVA $>4 \mathrm{~cm}$ & 3.2 & $0.9-10.3$ \\
\hline$>9$ levels in maximal thoracic kyphosis & 2.01 & $1.1-4.1$ \\
\hline Baseline C2-T3 SVA $>5.4 \mathrm{~cm}$ & 1.01 & $0.9-1.1$ \\
\hline Baseline PT $>20^{\circ}$ & 0.92 & $0.85-0.98$ \\
\hline
\end{tabular}

${ }^{*}$ AUC $=86 \%$.

† Gait impairment, hand numbness and clumsiness, and weakness were the most common

Her risk factors for a poor outcome included the following combination of factors: osteoporosis, baseline C2-T3 SVA of $107.9 \mathrm{~mm}$, baseline SVA of $131.8 \mathrm{~mm}$, and 12 levels in maximal thoracic kyphosis. Postoperatively, this patient had residual TS-CL (preoperative: $53.9^{\circ}$; postoperative: $26.7^{\circ}$ ) and cSVA (preoperative: $47.9 \mathrm{~mm}$; postoperative: $41.9 \mathrm{~mm}$ ) malalignment, failed to reach MCID for mJOA (preoperative score: 13; postoperative score: 10) and NDI (preoperative score: 62; postoperative score: 54 ), and experienced a postdischarge major mental status change.

\section{Discussion}

Outcomes after CD surgery are variable, with complications occurring commonly in complex deformity correction cases. With increased age, high comorbidity burden, and increased frailty, these CD patients are at high risk of experiencing poor outcomes after surgery. There is limited literature regarding the specific baseline demographic, clinical, and surgical factors that can be used to predict a poor overall outcome following CD surgery. Therefore, in this investigation we developed a predictive model for this CD cohort to predict poor radiographic and clinical outcomes as well as complications. In our cohort of CD patients, $20.2 \%$ of patients experienced an overall poor outcome.

An overall poor outcome was predicted with high accuracy (AUC 86\%) using a combination of demographic, clinical, and surgical factors. In looking specifically at the radiographic poor outcome, we found that $73 \%$ of patients had a severe TS-CL, while only $8 \%$ of CD patients had a severe cSVA by the 1-year follow-up. This suggests that TS-CL better captures the deformity of these patients and should be used above cSVA to gauge CD. ${ }^{1,2}$ Additional preoperative radiographic predictors of a poor outcome included severe C2-T3 SVA, global (C7-S1) SVA, and pelvic tilt. Given that these predictors take into account the global deformity of the spine beyond the cervical spine, these results suggest that severe full-spine malalignment impacts outcomes following CD corrective surgery and should be addressed appropriately. One recent study of surgical CD patients demonstrated that both cervical and global radiographic parameters were predictive of the postoperative complication of distal junctional kyphosis in the CD cohort. ${ }^{15}$ Other studies have also shown that global alignment affects the cervical spine and that in a thoracolumbar deformity population, both cervical and global sagittal alignment parameters are predictive of worse CD. ${ }^{13,14}$ Additionally, the predictor showed that having more than 9 vertebral levels in the preoperative maximal
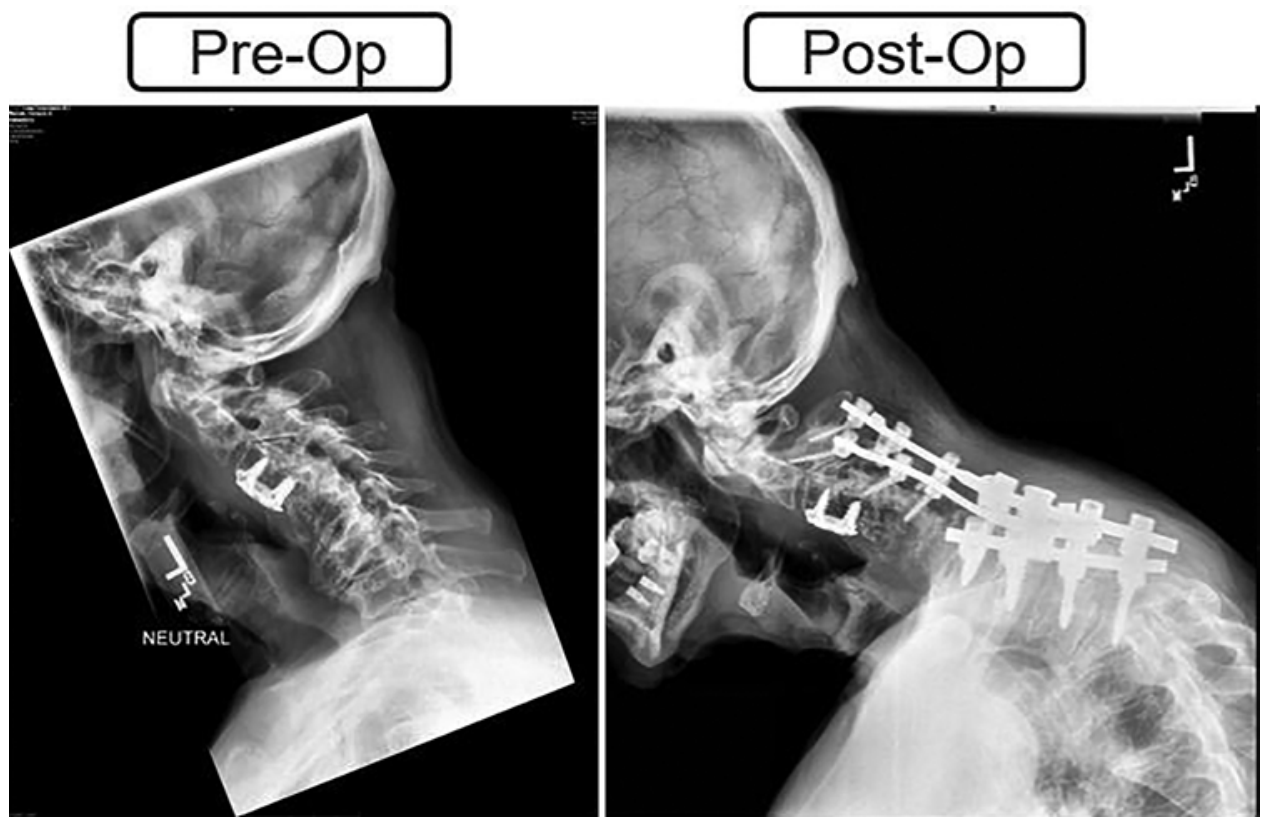

FIG. 2. Case example of a 69 -year-old male patient with $C D$ with a prior anterior fusion who underwent a posterior fusion from $\mathrm{C} 2$ to T4. His risk factors for a poor outcome included the following combination of factors: baseline neurological deficit (weakness, gait impairment, hand muscle atrophy), baseline C2-T3 SVA of $84.7 \mathrm{~mm}$, baseline pelvic tilt of $18.1^{\circ}$, and 12 levels in his maximal thoracic kyphosis. Postoperatively, this patient had worsening TS-CL and CSVA malalignment, and failed to reach MCID for the mJOA score, but his NDI score improved. This patient developed distal junctional kyphosis by 6 months postoperatively and required a reoperation. 


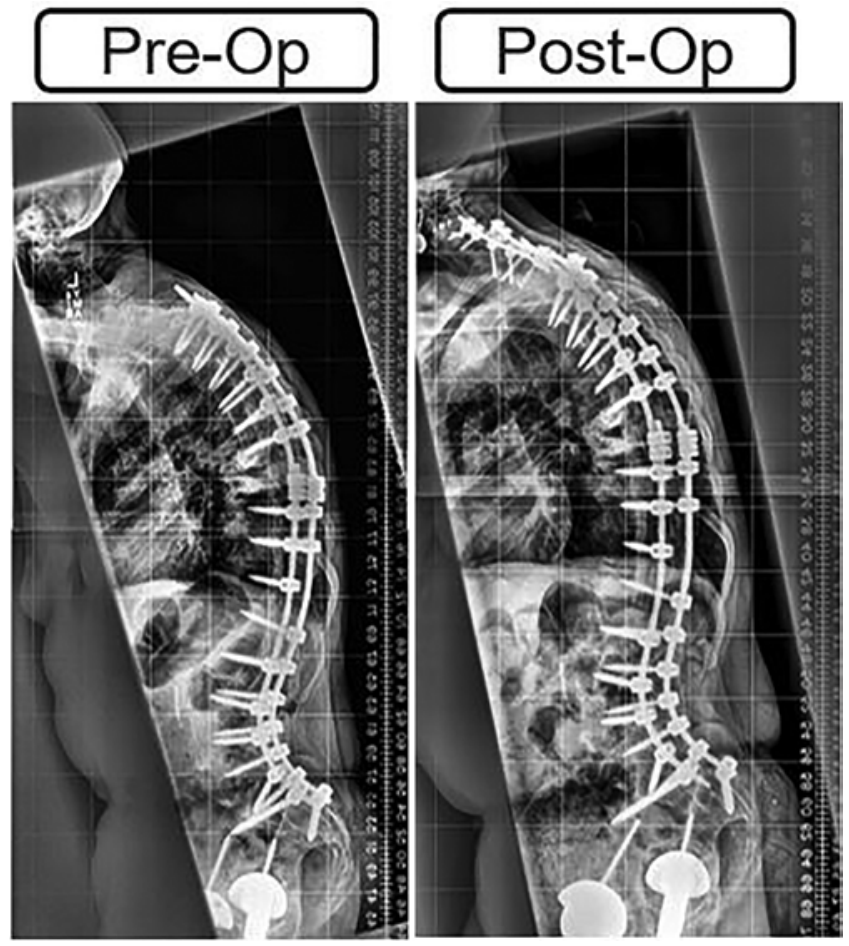

FIG. 3. Case example of 63-year-old female patient with $\mathrm{CD}$ with a prior thoracolumbar fusion who underwent a posterior fusion from $\mathrm{C} 5$ to T2. Her risk factors for a poor outcome included the following factors: osteoporosis, baseline C2-T3 SVA of $107.9 \mathrm{~mm}$, baseline SVA of 131.8 $\mathrm{mm}$, and 12 levels in her maximal thoracic kyphosis. Postoperatively, this patient had residual TS-CL and CSVA malalignment, failed to reach MCID for the MJOA and NDI scores, and experienced a postdischarge major mental status change.

thoracic kyphosis is an important consideration for surgical planning when determining the lowest instrumented vertebra and also in distal junctional kyphosis prediction in this cohort of patients.

Osteoporosis is a large problem globally, with more than 10 million individuals currently diagnosed, of whom about $80 \%$ are women. ${ }^{4,6,11}$ In our cohort of CD patients, osteoporosis was a strong predictor of a poor overall outcome (OR 5.9). Of our patients, $65 \%$ were women with an average age of 62 years, suggesting that this cohort is a high-risk group for osteoporosis. Previous studies on patients with degenerative thoracolumbar pathologies have shown a negative impact of osteoporosis on surgical outcomes given its impact on bone quality through negative bone remodeling and ultimate reduction in fusion rates and increased risk of fractures. ${ }^{3,7,8}$ However, limited literature exists that is specific to a CD population regarding the effects of osteoporosis on outcomes. This is the first study to date to report osteoporosis as a strong predictor of a poor overall outcome following CD corrective surgery. This highlights the important role of preoperative counseling and a multidisciplinary approach to osteoporotic patients to minimize poor outcomes.

Baseline neurological deficit was another significant predictor of an overall poor outcome, possibly resulting from changes in patients' neurological function and balance maintenance that might lead to altered postural alignment.
Their neurological compromise at baseline might also lead to decreased mobility, which would lead to a slower and poorer recovery. This could also in part be explained by the fact that the majority of these patients are elderly, with a high rate of osteoporosis and other age-related degenerative problems that can manifest in neurological symptoms such as cervical myelopathy. Additionally, a recent study demonstrated that $C D$ has a substantial health impact on this population, with the $\mathrm{CD}$ patients in that study having a mean EQ-5D score that was comparable to the bottom 25 th percentile of scores for other cohorts, including renal failure, stroke, and emphysema patients..$^{23}$ The substantial health impact of CD on these patients, in conjunction with previous studies that have shown that $\mathrm{CD}$ patients have a wide range of comorbidities and frailty indicators that put patients at risk for complications, could contribute to the occurrence of an overall poor outcome. ${ }^{9}$ It is also worth noting that although the rate of an overall poor outcome was $20.2 \%$, when looking individually at the rates of a suboptimal outcome for each specific factor (radiographic, clinical, or complications/reoperation), the rates of poor outcomes are much higher. This study is investigating the worst possible outcome, where patients have severe radiographic and clinical outcomes, as well as a complication, reoperation, or death; however, the less-severe poor outcomes are still worth highlighting, given their negative effect on overall patient health.

\section{Limitations}

This study has several potential limitations. The retrospective nature of this study may in some ways limit our findings; however, the generalizability of our study is reasonable given the fact that the patients were enrolled from centers across the continental United States. Additionally, MR images were not available for all patients to assess pre- and postoperative muscle, disc, or ligamentous contributions to the deformity or neurological deficit. The EQ$5 \mathrm{D}$ is an overall health-related quality of life assessment tool, the mJOA scale is validated for use in myelopathy patients, and the NDI is not CD-specific. Thus, our results might suggest that the common outcome assessment tools used in the CD literature are not entirely appropriate to capture clinical improvement for CD patients. This study is also in part limited by the lack of granularity regarding neurological abnormalities. Additionally, selection bias may limit the study, as there were only 13 study centers over a 5-year period, not all patients were enrolled, and 65 patients were lost to follow-up. Future research should evaluate the combination of risk factors for improved predictive strength and to glean a better understanding of the relationship of these factors in combination that predicts a poor outcome after CD surgery.

\section{Conclusions}

A total of $20.2 \%$ of CD patients had an overall poor outcome by 1 year postoperatively, defined as severe radiographic alignment, a poor clinical outcome, and a complication, reoperation, or death. A poor outcome was predicted with high accuracy using a combination of clinical, neurological, surgical, and radiographic factors, most 
notably osteoporosis, global SVA, and C2-T3 SVA. These results may assist in preoperative risk assessments and counseling for patients and surgeons in an attempt to mitigate the rates of poor outcomes in this population.

\section{Appendix}

\section{Members of ISSG Involved in This Study}

Peter G. Passias, MD, Virginie Lafage, PhD, Justin S. Smith, MD, Breton Line, BS, Neel Anand, MD, Justin K. Scheer, MD, Robert Eastlack, MD, Vedat Deviren, MD, Praveen V. Mummaneni, MD, Alan H. Daniels, MD, Han Jo Kim, MD, Eric O. Klineberg, MD, Douglas C. Burton, MD, Robert A. Hart, MD, Frank J. Schwab, MD, Shay Bess, MD, Christopher I. Shaffrey, MD, and Christopher P. Ames, MD.

\section{References}

1. Ames CP, Blondel B, Scheer JK, Schwab FJ, Le Huec JC, Massicotte EM, et al: Cervical radiographical alignment: comprehensive assessment techniques and potential importance in cervical myelopathy. Spine (Phila Pa 1976) 38 (22 Suppl 1):S149-S160, 2013

2. Ames CP, Smith JS, Eastlack R, Blaskiewicz DJ, Shaffrey CI, Schwab F, et al: Reliability assessment of a novel cervical spine deformity classification system. J Neurosurg Spine 23:673-683, 2015

3. Carreon LY, Puno RM, Dimar JR II, Glassman SD, Johnson JR: Perioperative complications of posterior lumbar decompression and arthrodesis in older adults. J Bone Joint Surg Am 85:2089-2092, 2003

4. Cauley JA, Fullman RL, Stone KL, Zmuda JM, Bauer DC, Barrett-Connor E, et al: Factors associated with the lumbar spine and proximal femur bone mineral density in older men. Osteoporos Int 16:1525-1537, 2005

5. Champain S, Benchikh K, Nogier A, Mazel C, Guise JD, Skalli W: Validation of new clinical quantitative analysis software applicable in spine orthopaedic studies. Eur Spine J 15:982-991, 2006

6. Hart RA, Prendergast MA: Spine surgery for lumbar degenerative disease in elderly and osteoporotic patients. Instr Course Lect 56:257-272, 2007

7. Kim DH, Vaccaro AR: Osteoporotic compression fractures of the spine; current options and considerations for treatment. Spine J 6:479-487, 2006

8. Kim WJ, Lee ES, Jeon SH, Yalug I: Correction of osteoporotic fracture deformities with global sagittal imbalance. Clin Orthop Relat Res 443:75-93, 2006

9. Miller EK, Ailon T, Neuman BJ, Klineberg EO, Mundis GMJ $\mathrm{Jr}$, Sciubba DM, et al: Assessment of a novel adult cervical deformity frailty index as a component of preoperative risk stratification. World Neurosurg 109:e800-e806, 2018

10. O’Brien MF, Kuklo TR, Blanke KM, Lenke LG (eds): Spinal Deformity Study Group Radiographic Measurement Manual. Winter Park, FL: Medtronic Sofamor Danek, 2008

11. Park SB, Chung CK: Strategies of spinal fusion on osteoporotic spine. J Korean Neurosurg Soc 49:317-322, 2011

12. Passias PG, Bortz C, Horn S, Segreto F, Poorman G, Jalai C, et al: Drivers of cervical deformity have a strong influence on achieving optimal radiographic and clinical outcomes at 1 year after cervical deformity surgery. World Neurosurg 112:e61-e68, 2018

13. Passias PG, Oh C, Jalai CM, Worley N, Lafage R, Scheer JK, et al: Predictive model for cervical alignment and malalignment following surgical correction of adult spinal deformity. Spine (Phila Pa 1976) 41:E1096-E1103, 2016

14. Passias PG, Soroceanu A, Scheer J, Yang S, Boniello A, Smith JS, et al: Magnitude of preoperative cervical lordotic compensation and C2-T3 angle are correlated to increased risk of postoperative sagittal spinal pelvic malalignment in adult thoracolumbar deformity patients at 2-year follow-up. Spine J 15:1756-1763, 2015

15. Passias PG, Vasquez-Montes D, Poorman GW, Protopsaltis T, Horn SR, Bortz CA, et al: Predictive model for distal junctional kyphosis after cervical deformity surgery. Spine J 18:2187-2194, 2018

16. Protopsaltis TS, Stekas N: Response to the Letter to the Editor regarding "Analysis of Successful vs. Failed Radiographic Outcomes Following Cervical Deformity Surgery." Spine (Phila Pa 1976) 43:E981-E982, 2018

17. Rillardon L, Levassor N, Guigui P, Wodecki P, Cardinne L, Templier A, et al: [Validation of a tool to measure pelvic and spinal parameters of sagittal balance.] Rev Chir Orthop Reparatrice Appar Mot 89:218-227, 2003 (French)

18. Scheer JK, Ames CP, Deviren V: Assessment and treatment of cervical deformity. Neurosurg Clin N Am 24:249-274, 2013

19. Scheer JK, Passias PG, Sorocean AM, Boniello AJ, Mundis GMJ Jr, Klineberg E, et al: Association between preoperative cervical sagittal deformity and inferior outcomes at 2-year follow-up in patients with adult thoracolumbar deformity: analysis of 182 patients. J Neurosurg Spine 24:108-115, 2016

20. Scheer JK, Tang JA, Smith JS, Acosta FL Jr, Protopsaltis TS, Blondel B, et al: Cervical spine alignment, sagittal deformity, and clinical implications: a review. J Neurosurg Spine 19:141-159, 2013

21. Smith JS, Klineberg E, Shaffrey CI, Lafage V, Schwab FJ, Protopsaltis T, et al: Assessment of surgical treatment strategies for moderate to severe cervical spinal deformity reveals marked variation in approaches, osteotomies, and fusion levels. World Neurosurg 91:228-237, 2016

22. Smith JS, Lafage V, Schwab FJ, Shaffrey CI, Protopsaltis T, Klineberg E, et al: Prevalence and type of cervical deformity among 470 adults with thoracolumbar deformity. Spine (Phila Pa 1976) 39:E1001-E1009, 2014

23. Smith JS, Line B, Bess S, Shaffrey CI, Kim HJ, Mundis G, et al: The health impact of adult cervical deformity in patients presenting for surgical treatment: comparison to United States population norms and chronic disease states based on the EuroQuol-5 Dimensions questionnaire. Neurosurgery 80:716-725, 2017

24. Smith JS, Ramchandran S, Lafage V, Shaffrey CI, Ailon T, Klineberg E, et al: Prospective multicenter assessment of early complication rates associated with adult cervical deformity surgery in 78 patients. Neurosurgery 79:378-388, 2016

\section{Disclosures}

The ISSG is funded through research grants from DePuy Synthes, which supported the current work.

Ms. Horn: consultant for Medicrea and SpineWave; scientific advisory board and speaking/teaching for Allosource, Zimmer Biomet, and Globus; and support of non-study-related clinical or research effort from CSFS and Aesculap. Dr. Lafage: direct stock ownership in Nemaris Inc.; speaking/teaching arrangements with AOSpine and DePuy Spine; and support of non-study-related clinical or research effort from DePuy Spine, NuVasive, K2M, and Stryker paid through ISSG and grants from SRS and NASS. Dr. Smith: consultant for K2M, AlloSource, Cerapedics, Zimmer Biomet, and NuVasive; support of non-study-related clinical or research effort from DePuy/Synthes/ISSG; royalties from Zimmer Biomet; and fellowship funding from NREF and AOSpine. Mr. Line: consultant for ISSG and AlloSource. Dr. Anand: consultant for Medtronic, direct stock ownership in Medtronic and Globus Medical, patent holder with Medtronic, and royalties from Globus Medical. Dr. Deviren: consultant for NuVasive, SeaSpine, Medi- 
crea, Pfizer, Biomet, Guidepoint, and Alphatec and royalties from NuVasive. Dr. Mummaneni: consultant for Stryker; employee of UCSF, royalties from DePuy, honorarium from Globus, ownership in ISD/Spinicity, and grants from AANS/CNS/AOSpine and NREF. Dr. Daniels: consultant for Spineart, Stryker, and Orthofix and royalties from Springer. Dr. Park: consultant for Globus, NuVasive, Medtronic, and Allosource and royalties from Globus. Dr. Nunley: consultant for K2M; direct stock ownership in Amedica, Paradigm, and Spineology; patent holder with K2M and LDR/Zimmer Biomet; speakers bureau for K2M and LDR/ Zimmer Biomet; Dr. Klineberg: consultant for DePuy Synthes, Stryker, Springer, Trevena, and Allosource; honoraria from K2M and AOSpine; and fellowship grant from AOSpine. Dr. Burton: consultant for Allosource and support of non-study-related clinical or research effort from Pfizer and DePuy. Dr. Schwab: consultant for MSD, K2M, Zimmer Biomet, NuVasive, and Medicrea; direct stock ownership in Nemaris Inc.; patent holder with MSD and K2M; support of non-study-related clinical or research effort from DePuy Spine, Stryker, K2M, and NuVasive (paid through ISSG); and speaking/teaching arrangements with MSD, K2M, NuVasive, and Zimmer Biomet. Dr. Bess: consultant for K2M and Allosource; royalties from K2M; and support of non-studyrelated clinical or research effort from K2M, Innovasis, NuVasive, DePuy, and Stryker. Dr. Shaffrey: consultant for Medtronic and NuVasive; direct stock ownership in NuVasive; and patent holder with Medtronic, NuVasive, and Zimmer Biomet. Dr. Ames: employee of UCSF; consultant for Medtronic, Stryker, Medicrea, K2M, and DePuy Synthes; and royalties from Stryker, Biomet Spine; DePuy Synthes; NuVasive; and Next Orthosurgical.

\section{Author Contributions}

Conception and design: Passias, Horn, Oh, V Lafage, R Lafage, Smith, Line, Anand, Segreto, Bortz, Scheer, Eastlack, Deviren, Mummaneni, Daniels, Park, Nunley, Kim, Klineberg, Burton,
Hart, Schwab. Acquisition of data: Passias, Horn, V Lafage, R Lafage, Smith, Line, Anand, Eastlack, Deviren, Mummaneni, Daniels, Park, Nunley, Kim, Klineberg, Burton, Hart, Schwab, Bess. Analysis and interpretation of data: Passias, Horn, Oh, V Lafage, R Lafage, Line, Segreto, Scheer. Drafting the article: Passias, Horn, Oh, Bortz, Daniels, Bess, Ames. Critically revising the article: Passias, Horn, Oh, V Lafage, R Lafage, Smith, Line, Anand, Segreto, Bortz, Scheer, Eastlack, Deviren, Mummaneni, Daniels, Park, Kim, Klineberg, Bess, Shaffrey. Reviewed submitted version of manuscript: Passias, Horn, Oh, V Lafage, R Lafage, Smith, Line, Anand, Segreto, Bortz, Scheer, Eastlack, Deviren, Mummaneni, Daniels, Park, Nunley, Kim, Klineberg, Burton, Hart, Schwab. Approved the final version of the manuscript on behalf of all authors: Passias. Statistical analysis: Passias, Horn, Oh, R Lafage, Scheer, Shaffrey. Administrative/ technical/material support: Passias, V Lafage, Smith, Line, Nunley, Klineberg, Burton, Hart, Schwab, Ames. Study supervision: Passias, V Lafage, Burton, Hart, Schwab.

\section{Supplemental Information Previous Presentations}

Portions of this study were presented at the 34th Annual Meeting Cervical Spine Research Society-Europe, Lisbon, Portugal, May 11, 2018.

\section{Correspondence}

Peter G. Passias: New York Spine Institute, NYU Langone Medical Center-Orthopaedic Hospital, New York, NY. peter. passias@nyumc.org. 